\title{
Strain and vorticity analysis using small-scale faults and associated drag folds
}

\author{
Enrique Gomez-Rivas a,", Paul D. Bons ${ }^{\mathrm{b}}$, Albert Griera ${ }^{\mathrm{c}}$, Jordi Carreras ${ }^{\mathrm{a}}$, Elena Druguet ${ }^{\mathrm{a}}$ \\ and Lynn Evans \\ ${ }^{a}$ Departament de Geologia, Universitat Autònoma de Barcelona, 08193 Bellaterra (Barcelona), Spain \\ ${ }^{b}$ Mineralogie und Geodynamik, Institut für Geowissenschaften, Eberhard Karls Universität, Sigwartstr. 10, 72076 Tübingen, \\ Germany \\ ${ }^{c}$ Laboratoire des Mécanismes et Transferts en Géologie, Université Paul-Sabatier, 14 Ave Edouard Belin, 31400 Toulouse \\ cedex, France \\ ${ }^{d}$ School of Earth Sciences, University of Melbourne, Victoria, 3010, Australia \\ * Corresponding author. Tel: +34-935811163; Fax: +34-935811263; E-mail address: enrique@gomez-rivas.info
}

Published in Journal of Structural Geology, 29, 1882-1899. doi:10.1016/j.jsg.2007.09.001

This is the author's version of the manuscript. You can access the copy-edited version at: http://www.sciencedirect.com/science/article/pii/S0191814107001642

\begin{abstract}
Small-scale faults with associated drag folds in brittle-ductile rocks can retain detailed information on the kinematics and amount of deformation the host rock experienced. Measured fault orientation $(\alpha)$, drag angle $(\beta)$ and the ratio of the thickness of deflected layers at the fault $(L)$ and further away $(T)$ can be compared with $\alpha, \beta$ and $L / T$ values that are calculated with a simple analytical model. Using graphs or a numerical best-fit routine, one can then determine the kinematic vorticity number and initial fault orientation that best fits the data. The proposed method was successfully tested on both analogue experiments and numerical simulations with BASIL. Using this method, a kinematic vorticity number of one (dextral simple shear) and a minimum finite strain of 2.5 to 3.8 was obtained for a population of antithetic faults with associated drag folds in a case study area at Mas Rabassers de Dalt on Cap de Creus in the Variscan of the easternmost Pyrenees, Spain.
\end{abstract}

Keywords: strain analysis; vorticity; progressive deformation; faults; drag folds; foliation.

\section{Introduction}

One of the aims of structural geology is to determine and quantify the amount and type of deformation that rocks experienced. For this structural geologist use a variety of structures that record deformation, such as folds, boudins, veins, etc. (e.g. Ramsay and Huber, 1983). In this paper we propose a new method to determine finite strain and the kinematics of deformation using isolated, discrete smallscale faults and their associated drag folds.

Slip along a fault will cause heterogeneous deformation in the vicinity of the fault. Drag folds are the usual result in foliated rocks. Recently, much attention has been given to small-scale faults and their associated drag folds in mostly ductile rocks (Passchier, 2001; Grasemann and Stüwe, 2001; Grasemann et al., 2003; Exner et al., 2004; Grasemann et al., 2005; Wiesmayr and Grasemann, 2005; Coelho at al., 2005; Kocher and Mancktelow, 2006). In the modern literature, these structures were first described by Gayer et al. (1978) and Hudleston (1989). These structures were later dubbed "flanking folds" or "flanking structures" by Passchier (2001), who used this term for a variety of structures apart from fault-related drag folds. Instead of this new terminology, we prefer to use well-known and long-used terms: faults and drag folds.

The aforementioned authors described a range of drag fold structures and proposed a 
number of classification schemes. Basically, an isolated fault with its associated drag folds falls into one of four categories by the combination of two parameters: fault movement is antithetic (a-type of Grasemann et al., 2003) or synthetic (s-type) with regard to the far-field sense of shear, and drag folds are normal or reverse with regard to the slip along the fault. Of these four, the antithetic reverse-drag category is the most common for isolated faults. The fact that reverse drag is common is to be expected for isolated faults in an otherwise homogeneously deforming medium. A straight foliation element (layering, cleavage) that is cut by the fault will remain on a single straight plane away from the fault, whereas close to the fault, it is bent by the fault movement (Fig. 1a). Both synthetic and antithetic faults will therefore initially develop reverse-drag folds. However, Exner et al. (2004) showed that the slip direction may change at a high strain and reverse drag folds then become normal drag folds.

An isolated, discrete fault will typically develop drag folds with a constant sign of curvature. In a ductile shear band (i.e. minor shear zone) the foliation is not cut by a fault, but can be traced continuously through the shear band (Fig. 1b). This implies that there is an inflexion point where curvature changes sign (Coelho et al., 2005). This produces shear-band type structures in the terminology of Wiesmayr and Grasemann (2005). However, these structures still exhibit the same reverse or normal drag on a larger scale than the deflection caused by the localised shearing within the shear band. These reversedrag folds can usually not be discerned when shear band spacing is on the same scale as the reverse drag folds.

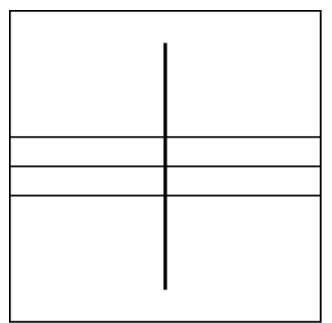

(a) discrete fault
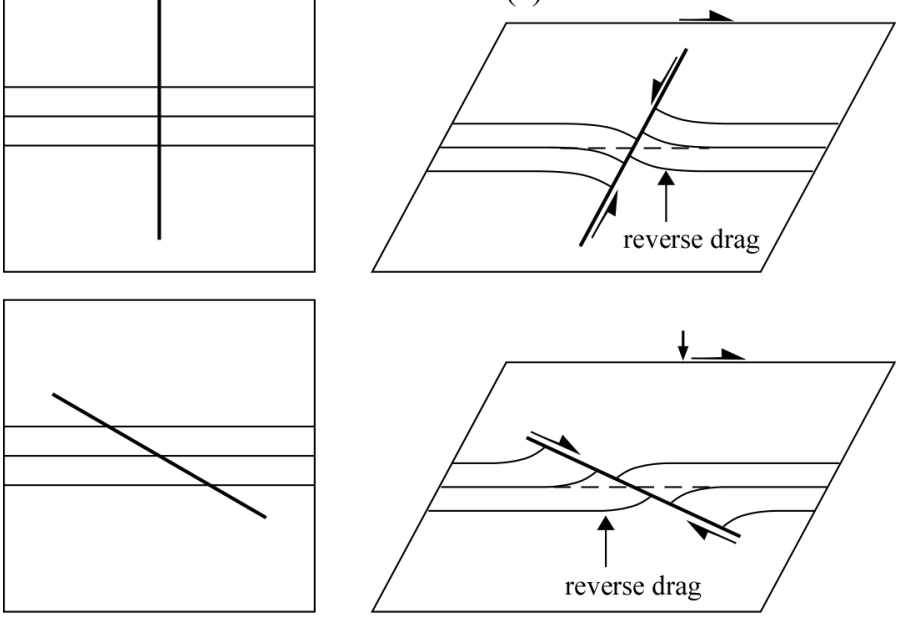

(b) ductile shear band
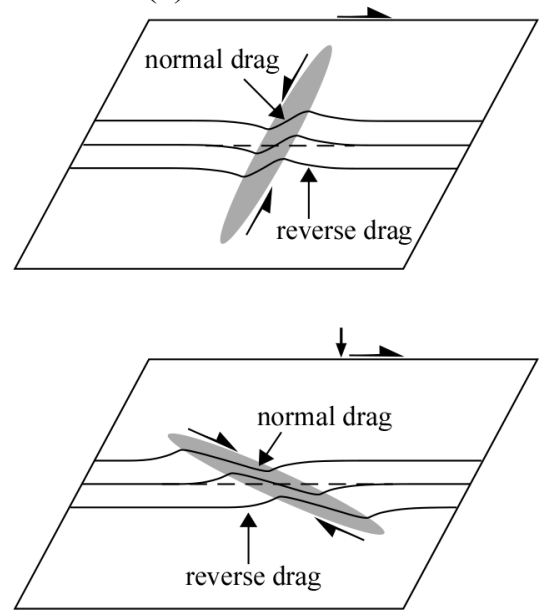

Fig. 1. Schematic illustration of the formation of reverse-drag folds adjacent to (a) isolated faults and (b) shear bands in a general shear field $(W k=0.64)$ that is homogeneous far away from the fault/shear band. In case of a ductile shear band, normal drag is found within the shear band, in addition to reverse drag away from the shear band. The same applies to antithetic movement (top) and to synthetic movement (bottom). Left column shows the geometry before deformation.

Despite the several field studies (Gayer et al., 1978; Druguet et al., 1997; Harris, 2003), as well as numerical (Grasemann and Stüwe, 2001; Grasemann et al., 2003; Grasemann et al., 2005; Wiesmayer and Grasemann, 2005; Coelho et al., 2005; Kocher and Mancktelow, 2006) and experimental simulations (Hudleston, 1989; Odonne, 1990;
Koyi and Skelton, 2001; Harris et al., 2002; Exner et al., 2004; Kocher and Mancktelow, 2006) of drag fold structures, so far only Kocher and Mancktelow (2005) proposed a way to use these structures to quantify the finite strain and kinematics of deformation. They employed the analytical solution of Schmid and Podladchikov (2003) for the 
deformation field along an isolated fault that itself is passively deformed by the applied bulk flow. Their method is essentially applying the reverse model strain field to straighten out the foliation. Since bulk deformation kinematics and finite strain are not known a priori, a range of finite strains and vorticities are applied and the one that best straightens the foliation is chosen as the solution. The advantage of the method is that a single structure can be used to determine the vorticity of deformation, the finite strain since formation of the fault, and the original orientation of the fault relative to the foliation. A disadvantage is that appropriate software is needed.

In this paper we propose a similar method to determine these three parameters. The advantage of our proposed method is that the method does not necessarily require a computer. Instead, charts can be used, which means the method can easily be applied in the field. However, a more accurate determination can only be achieved numerically, as is described in this paper. A disadvantage is that multiple fault-drag fold structures are needed at different stages of development (finite strain since formation). This study is based on a population of drag fold structures in deformed quartzites from Mas Rabassers de Dalt on the Cap de Creus Peninsula in north-eastern Spain (Fig. 2). These structures and their setting will be described first to provide the background for the method that is described in the subsequent sections.

\section{Examples from the Rabassers quartzite}

\subsection{Regional setting of the Mas Rabassers de Dalt locality}

The Cap de Creus Peninsula is the easternmost outcrop of the Variscan basement exposed along the Axial Zone of the Pyrenees (Barnolas and Chiron, 1996; Carreras, 2001). The dominant lithology in the area of interest near the ruin of Mas Rabassers de Dalt (UTM $31 \mathrm{~N} 0523100,4685200$, Fig. 3) is a monotonous series of amphibolite-facies metaturbidites (Druguet, 1997; 2001). The rocks experienced multiple deformation phases during the Variscan Orogeny (Druguet, 1997; Druguet, 2001; Bons et al., 2004). Some quartzite beds, ranging from a few tens of centimetres to a few metres in thickness, are intercalated in the meta-turbidites. They form the only marker horizons that can be traced over distances of up to a few hundred metres. All the drag fold structures discussed in this paper were found in one such bed, which has a distinct black-and-white cm-scale banding (Fig. 2). The banding is layer-parallel and therefore assumed to be original sedimentary layering. The colour difference is a result of different amounts of graphite and other impurities, which also results in a difference in grain size between the layers (Fig. 2g-h). There are no indications for any significant differences in rheological properties between the dark and light bands (no cuspate-lobate structures, buckle folds in specific layers, etc.).

Near Mas Rabassers de Dalt, the quartzite and $S_{1}$ layer-parallel foliation $\left(S_{01}\right)$ are affected by two more folding events $\left(D_{2}\right.$ and $\mathrm{D}_{3}$ ), resulting in a complex exposure pattern (Druguet, 1997). Pegmatites that intruded during peak-metamorphic conditions (Druguet and Hutton, 1998) are only affected by retrograde $D_{3}$ folding and shearing. The regional trend of the $S_{01}$ main foliation is NWSE, when not affected by $\mathrm{D}_{3}$ shearing. A broad zone of dextral NW-SE-trending $\mathrm{D}_{3}$ shearing rotated $\mathrm{S}_{01}$ towards the NE-SW trend that dominates in the area shown in figure 3 . The curvature of the quartzite layer and the $S_{01}$ foliation is due to decametric folds predating the shearing event that can be recognized from the structural map. Localisation of the shearing led to the formation of a number of narrower $(\geq 10 \mathrm{~m})$ shear zones with distinctly elevated shear strain. Although the superposition of three deformation events makes it difficult to interpret the map pattern at Mas Rabassers de Dalt (Fig. 3), extensive mapping at the site and the region has unambiguously established the dextral nature of the $\mathrm{D}_{3}$ shearing and associated folding (Carreras and Casas, 1987; Carreras, 2001; Carreras et al., 2005; Fusseis et al., 2006). 
Gomez-Rivas, E., Bons, P.D., Griera, A., Carreras, J., Druguet, E., and Evans, L. (2007). Strain and vorticity analysis using small-scale faults and associated drag folds. Journal of Structural Geology, 29, 1882-1899
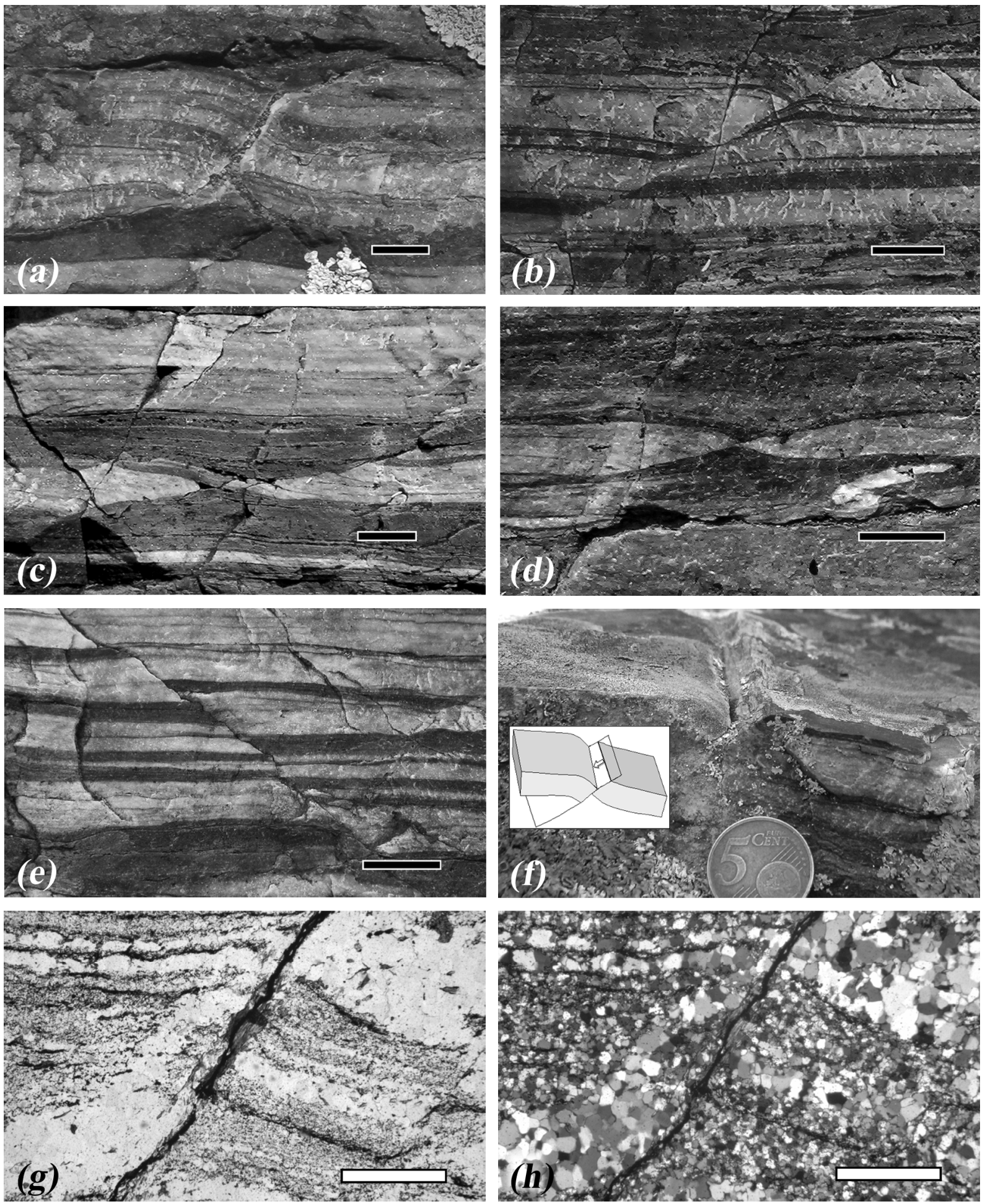

Fig. 2. Drag fold structures in the banded quartzite at Mas Rabassers de Dalt, Cap de Creus, Spain. Sense of shear is top (east) to the right. (a-d) Antithetic faults with reverse-drag folds at different stages of development. (e) One of the rare synthetic faults. (f) Photograph and sketch showing that in the third dimension the faults are straight and extend further than their length perpendicular to the banding. (g) Plane-polarised light micrograph of an antithetic fault. Variations in the content of graphite and mica particles form the dark and light bands. (h) Same image in crosspolarised light. Quartz grain size is largest in clean quartz. All images looking onto the surface perpendicular to the foliation and faults. Black scale bars $10 \mathrm{~mm}$, white scale bars $0.5 \mathrm{~mm}, \varnothing$ of $5 €$-cent coin is $21 \mathrm{~mm}$. 
Gomez-Rivas, E., Bons, P.D., Griera, A., Carreras, J., Druguet, E., and Evans, L. (2007). Strain and vorticity analysis using small-scale faults and associated drag folds. Journal of Structural Geology, 29, 1882-1899

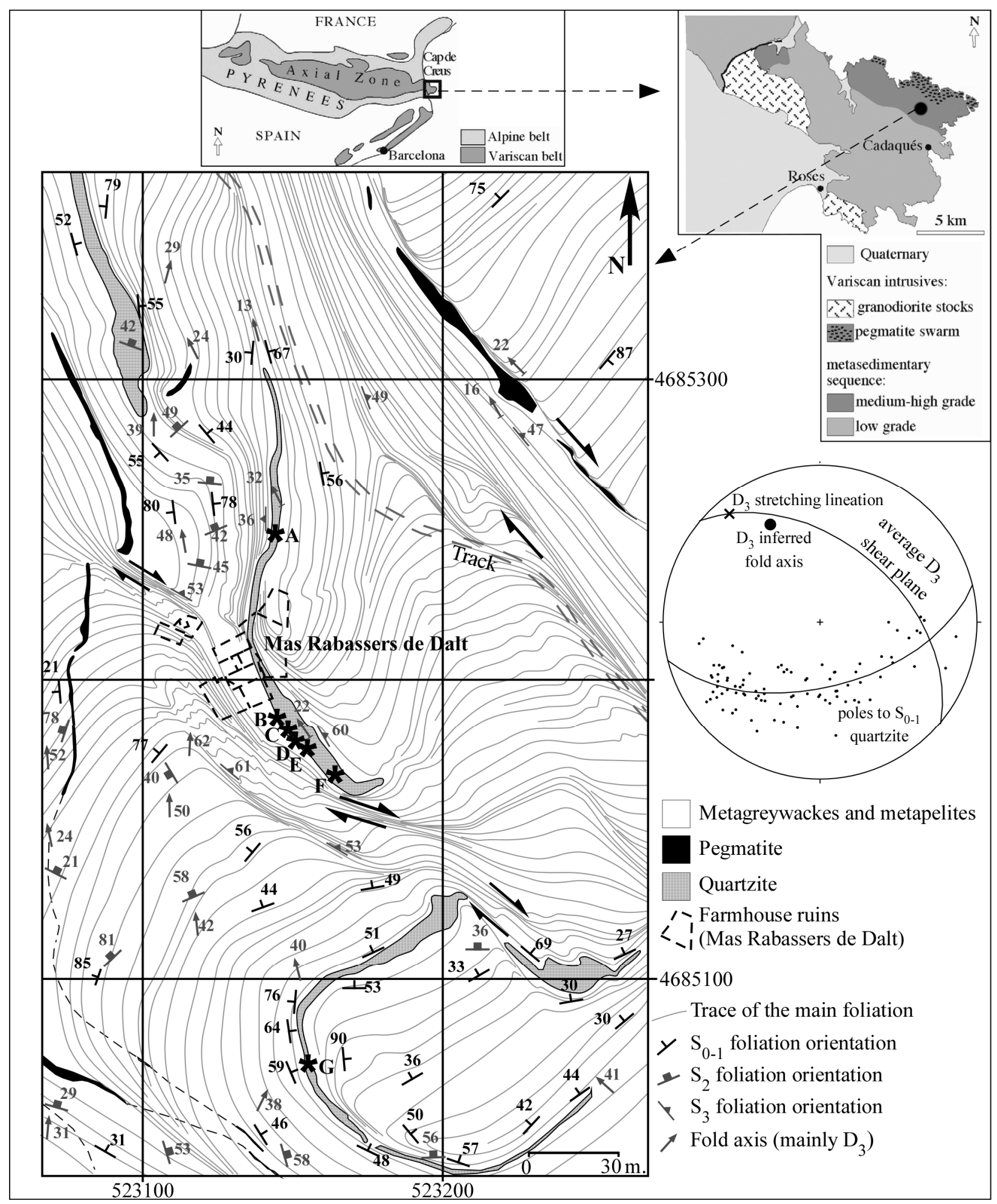

Fig. 3. Detailed map of the Mas Rabassers de Dalt Outcrop showing the refolded quartzite bed and the localities where the small-scale faults were found and measured. The stereoplot summarizes the main structural information: poles to quartzite bedding (open dots) that lie on great circle (dashed line) defining the $\mathrm{D}_{3}$ fold axis (closed dot) which lies on the great circle of the average $\mathrm{D}_{3}$ shear plane. The cross is the average $\mathrm{D}_{3}$ shear direction. Black arrows indicate sense of D3 shear zones. (Based on Druguet, 1997). 


\subsection{Drag fold structures}

The discrete faults with drag folds are mainly found in the refolded quartzite bed. Within that bed they only occur in sections of the bed that run roughly parallel to the $D_{3}$ shear zones. This suggests that they formed during $\mathrm{D}_{3}$ dextral shearing and not during earlier deformation events. Almost all (localities A-F in Fig. 3) occur in the western limb of a $\mathrm{D}_{2}$-fold, of which the hinge is skirted by one of the zones of most intense localised shearing.

The drag folds form at cm-scale, steeply plunging faults, best seen on gently dipping outcrop surfaces. Almost all drag folds are reverse. Faults with the least offset relative to their length are almost perpendicular to the banding in the quartzite (Fig 2a). More evolved structures make an increasingly smaller angle with the banding, suggesting the structures progressively rotated clockwise (Fig. 2c-d). Fault tips can rarely be discerned, as faults tend to bend in a listric form to become parallel to the banding at both ends. Dextral layer-parallel slip is observed in a few rare cases where crosscutting veins are offset. Clockwise rotation of the faults and layerparallel slip all indicate dextral shear. The faults are therefore interpreted as antithetic faults. Synthetic faults (Fig. 2e) are rare in the quartzite, and usually make a small angle with the banding. In the third dimension, the small faults are remarkably straight and may extend over more than a metre (Fig. 2f). Even on the microscopic scale, the faults are discrete planes with only a very narrow damage zone (Fig. 2g-h).

\section{Method}

The method described below is aimed at estimating the kinematic vorticity number (Means et al., 1980) and finite strain that the rock experienced using parameters of the drag fold structures that can be measured easily. The following parameters can be determined in the field (Fig. 4): the angle ( $\alpha$ ) between the fault and the far-field foliation, the drag angle $(\beta)$ between the foliation and the fault measured at the fault, preferably in the middle of the fault, and finally the ratio between the thickness of a marker layer at the fault, measured parallel to the fault $(L)$ at the fault, and perpendicular to the layer $(T)$ away from the fault. All parameters must be measured in the plane perpendicular to the fault and foliation.

The first main assumption is that the fault acts as a passive, straight marker line that is being rotated and stretched/shortened by the applied bulk flow. This assumption is validated by both numerical and physical experiments (Grasemann and Stüwe, 2001; Exner et al., 2004). Clearly, the four parameters will evolve from their initial values $\left(\alpha_{0}=\beta_{0}\right.$ and $\left.\mathrm{L}_{0} / \mathrm{T}_{0}=1 / \sin \left(\alpha_{0}\right)\right)$, depending on the flow field relative to the initial orientation of the fault and foliation. We need to know how $\alpha, \quad \beta$ and $L / T$ evolve, as a function of progressive deformation and initial conditions, to determine which initial conditions, kinematics of flow and finite strain lead to the combinations of $\alpha, \beta$ and $L / T$ that were measured in the field. However, there may not be a unique solution for any given single combination of $\alpha, \beta$ and $L / T$. This brings us to the second main assumption for the proposed method: during progressive deformation faults form at different stages, but with the same initial orientation $\left(\alpha_{0}\right)$. At the end of deformation (the state observed in the field), each fault experienced different amounts of deformation and is therefore in a different state of development (Fig. 2a-d). Analysis of several of such faults produces a number of different $\alpha, \beta$ and $L / T$ combinations. These measured combinations should lie on a path in $\alpha, \beta$ and $L / T$ space that is unique to the flow kinematics and initial orientation of the faults.

The basic idea of our proposed method is that theoretical paths for all flow kinematics and initial fault orientations can be determined, and can then be compared with $\alpha$, $\beta$ and $L / T$ data sets that are measured in the field. The path that best fits the data provides us with the flow kinematics and the initial fault orientation. It also allows us to determine which data point represents the highest strain, which gives a minimum estimate of the finite 
strain. Comparison of theoretical paths and data can be done using charts or with a computer program that carries out the best fit. The advantage of using charts is that they can easily be employed in the field.

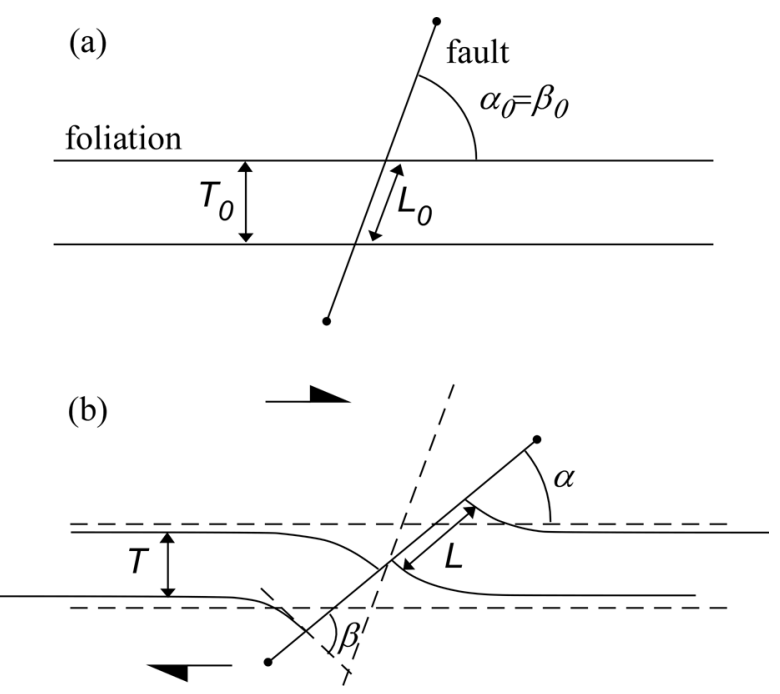

Fig. 4. Sketch showing a fault and drag fold in the undeformed (a) and deformed (b) stage, with all the parameters that are required for the analysis.

\subsection{Theoretical $\alpha-\beta-L / T$ paths}

The following analysis is based on the deformation at an isolated single straight fault in an otherwise homogenously deforming medium. The fault is supposed to have a limited extent, so that the offset reduces to zero at both ends. We consider a plane-strain case, with the fault oriented parallel to the intermediate principal stretching direction. The problem can therefore be regarded as twodimensional. If deformation is not plane strain, stretching or shortening in the third dimension would cause an area change in the section under consideration, but no changes in the angles and other parameters that are used below. We further consider an initially straight foliation perpendicular to the section under consideration.

Similar to Kocher and Mancktelow (2005), we fix our reference frame to be parallel and perpendicular to the far-field foliation orientation. The foliation is assumed to be parallel to a direction of zero rotation and therefore parallel to one of the flow eigenvectors or apophyses (Passchier, 1988;
Ebner and Grasemann, 2006). As in most studies, we assume that the kinematics of strain do not change during deformation. The bulk flow field is now given by the position gradient tensor $\mathbf{F}$ :

$$
\mathbf{F}=\left(\begin{array}{cc}
a & g \\
0 & 1 / a
\end{array}\right)
$$

where $a$ is the amount of stretching, and $g$ the amount of shearing, both parallel to the foliation. Because of the definition of the reference frame, the far field foliation does not rotate relative to the reference frame, but it may stretch or shorten if $a \neq 1$. F is areaconservative because of our assumption of plane-strain flow.

It is also assumed that the fault is frictionless, so that it cannot support any shear stress. This implies that the material adjacent to the fault stretches/shortens in pure shear parallel to the fault. Rotation of the fault adds a spin to the deformation, but deformation immediately adjacent to the fault plane remains coaxial. The no-friction assumption is unlikely to be completely valid in reality. However, our experiments and numerical simulations below show that small deviations in mechanical properties of the fault or shear zone do not noticeably change the outcome. Furthermore, the fault as a whole behaves as a passive plane, or a line in $2 \mathrm{D}$, and therefore stretches and shortens according to the bulk flow field. We define $e$ as the amount of stretch or longitudinal strain of the fault (its finite length / original length). With these assumptions an analytical solution exists for the evolution of $\alpha, \beta$ and $L / T$ for a layer that intersects the fault at its centre.

To determine the orientation of the fault with progressive strain, we consider a unit vector parallel to the fault. This vector has initial coordinates $\left[\cos \left(\alpha_{0}\right), \sin \left(\alpha_{0}\right)\right]$. After deformation, and due to the application of the tensor $\mathbf{F}$, the vector will have new coordinates $\left[a \cdot \cos \left(\alpha_{0}\right)+g \cdot \sin \left(\alpha_{0}\right),(1 / a) \cdot \sin \left(\alpha_{0}\right)\right]$. The stretch (e), parallel to the fault, is the ratio of the finite and original length of the unit vector:

$$
e=\sqrt{\left(a \cdot \cos \left(\alpha_{0}\right)+g \cdot \sin \left(\alpha_{0}\right)\right)^{2}+\frac{1}{a^{2}} \sin ^{2}\left(\alpha_{0}\right)}
$$


The finite orientation $(\alpha)$ of the fault relative to foliation is:

$$
\alpha=\arctan \left(\frac{\sin \left(\alpha_{0}\right)}{a^{2} \cdot \cos \left(\alpha_{0}\right)+a \cdot g \cdot \sin \left(\alpha_{0}\right)}\right)
$$

As deformation progresses the foliation is reoriented at the fault, describing a drag angle $(\beta)$ between the foliation and the fault plane. We use the assumption of a frictionless fault and therefore pure shear parallel to the fault. The foliation at the fault thus experiences a stretch $(e)$ parallel to the fault, while it passively rotates along with the fault. Stretching and rotation determine the drag angle. A local position gradient (F') tensor can be defined in a coordinate system parallel to the fault:

$$
\mathbf{F}^{\prime}=\left(\begin{array}{cc}
e & 0 \\
0 & 1 / e
\end{array}\right)
$$

A unit vector in this local coordinate system will change from initial coordinates $\left[\cos \left(\beta_{0}\right), \sin \left(\beta_{0}\right)\right]$ to new coordinates $\left[e \cdot \cos \left(\beta_{0}\right),(1 / e) \cdot \sin \left(\beta_{0}\right)\right]$. The angle $(\beta)$ between foliation at the fault and that fault will then be (using $\alpha_{0}=\beta_{0}$ ):

$$
\beta=\arctan \left(\frac{\sin \left(\beta_{0}\right)}{e^{2} \cdot \cos \left(\beta_{0}\right)}\right)=\arctan \left(\frac{\sin \left(a_{0}\right)}{e^{2} \cdot \cos \left(a_{0}\right)}\right)
$$

The reference layer should intersect the fault just at the centre of it, where the maximum displacement can be found. Away from the fault the finite thickness $(T)$ of that layer is a function of the bulk finite strain and its original thickness $\left(T_{0}\right)$ :

$$
T=\frac{T_{0}}{a}
$$

The initial fault-parallel thickness $\left(L_{0}\right)$ is:

$$
L_{0}=\frac{T_{0}}{\sin \left(\alpha_{0}\right)}
$$

This line $L_{0}$ gets stretched by the same amount (e) as the fault, so its length after deformation will be:

$$
L=e \cdot L_{0}=\frac{e \cdot T_{0}}{\sin \left(\alpha_{0}\right)}
$$

As the absolute dimensions are irrelevant for the geometry of the system, we combine equation (7) and (8) to obtain the ratio $L / T$ :

$$
L / T=\frac{e \cdot T_{0}}{\sin \left(\alpha_{0}\right)} \frac{a}{T_{0}}=\frac{e \cdot a}{\sin \left(\alpha_{0}\right)}
$$

We now have the three measurable parameters $\alpha, \beta$ and $L / T$ as a function of the unknown variables $\alpha_{0}, a$, and $g$. Although the combination of $a$ and $g$ defines the amount of finite strain and the kinematics of strain, it may be more useful to use the two variables finite strain ration $\left(R_{f}\right)$ and angle between the two flow apophyses on the vorticity-normal section $(\omega)$ or kinematic vorticity number $(W k) . R_{f}$ is the axial ratio of the finite strain ellipse and $\omega$ the angle between the flow apophyses, with:

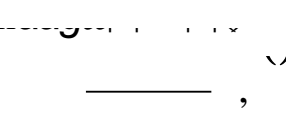

and

$$
R_{f}=\frac{2 \sqrt{g^{2}+\frac{1}{4}(1 / a+a)^{2}}+\sqrt{g^{2}+(a-1 / a)^{2}}}{2 \sqrt{g^{2}+\frac{1}{4}(1 / a+a)^{2}}-\sqrt{g^{2}+(a-1 / a)^{2}}}
$$

$\omega$ can range from $0^{\circ}$ for simple shear $(W k=1)$ to $+90^{\circ}$ for pure shear $(W k=0)$ stretching parallel to the foliation, or $-90^{\circ}$ for pure shear shortening parallel to the foliation.

With the above equations, curves of $\alpha$ and $L / T$ as a function of $\beta$ are shown for different vorticities and starting orientation of the fault (Fig. 5).

\subsection{Determining vorticity and initial fault angle with charts}

To determine the vorticity $(\omega)$ and initial fault orientation $\left(\alpha_{0}\right), \alpha, \beta$ and $L / T$ need to be 
measured on a population of faults with drag folds. Such data can be measured in the field or from pictures. The plane of observation should be perpendicular to both fault and foliation. If not, the apparent values should be corrected to get the true values. The data should be collected as close as possible to the middle of the fault, so that equation (2) holds for the stretching of the material immediately adjacent to the fault. It should also be noted that these equations can be only used when the fault is discrete. In case of a narrow ductile shear band, the angle $\beta$ would be modified due to shearing of the foliation in the narrow zone (Fig. 1b).

Applying the above equations, several unique graphs for the evolution of $\alpha, \beta$ and $L / T$ can be plotted for progressive strain, for a certain starting orientation of the fault $\left(\alpha_{0}\right)$ and a certain kinematic vorticity number $(W k)$ (Fig 5 ). Charts covering the full range of $\omega$ from 90 to $+90^{\circ}$ and $\alpha_{0}$ from 0 to $180^{\circ}$ are provided in the appendix. We assume that all the shear bands start off at different times, but with a similar orientation. Each fault then represents a different stage of development. The data can be plotted in each of the graphs of figure 5 . Ideally, all data should plot on a single curve that represents the evolution of a fault system with a certain $\alpha_{0}$ and $\omega$. The fault that experienced the least strain should lie closest to the estimated initial fault angle $\left(\alpha_{0}\right)$. The total amount of strain can be estimated from that for the most developed fault system. This is, of course, a minimum estimate, because even the most developed, oldest fault that is found must not necessarily have experienced the total finite strain of the host rock. The pair of curves in figure 5 that best fits the eight measurements is the one for $\omega=0^{\circ}$ (simple shear) and $\alpha_{0}$ is $70^{\circ}$ to $80^{\circ}$. The highest strain the rock experienced is estimated to be between $R_{f}=8$ and 16 , which corresponds to a dextral shear strain of 2.5 to 3.8 .

Figure 5 shows that the curves for different $\alpha_{0}$ and $\omega$ are distinct, as long as $\alpha_{0}$ is larger than about $40^{\circ}$. This means that the method is only applicable to faults that started off at a high angle to the foliation.

\subsection{Numerical implementation of the method}

Finding the curve that best fits the data can also be done numerically, using a least-squares approach. A small program that does the curve fitting was written in the language " $\mathrm{C}$ " (source code can be obtained from the authors). Input is a text file containing a list of $\alpha, \beta$ and $L / T$ data. The program cycles through all possible kinematic vorticity numbers $(-1$ to +1$)$ and $\alpha_{0}$ angles $\left(0\right.$ to $\left.180^{\circ}\right)$, each with increments of $1^{\circ}$. For each $\omega$ and $\alpha_{0}$ combination, the program then calculates the $\alpha-\beta-L / T$ curve for progressive strain, increasing strain in small increments. For each strain increment and each $i$-th data point, the difference $\Delta_{i}$ between the theoretical and measured $\alpha, \beta, L / T$ values is calculated:

$$
\Delta_{i\left(\alpha_{0}, \omega, R f\right)}=\sqrt{\begin{array}{l}
\left(\alpha_{c}-\alpha_{i}\right)^{2}+\left(\beta_{c}-\beta_{i}\right)^{2} \\
+w\left(L / T_{c}-L / T_{i}\right)^{2}
\end{array}}
$$

Here the subscript $c$ stands for theoretical values and $i$ for measured data. Because the range of $L / T$ values differs from that of the angles $\alpha$ and $\beta, L / T$ data may be given a different weighting $(w)$ for the leastsquares best fit. For a given $\omega$ and $\alpha_{0}$ combination, the sum $\left(\Sigma \Delta_{i}\right)$ of the smallest $\Delta_{i^{-}}$ value for each data point is a measure of how well that $\omega$ and $\alpha_{0}$ combination fits the data. The $\omega$ and $\alpha_{0}$ combination with the lowest $\Sigma \Delta_{i}$ is regarded as the best estimate of $\omega$ and $\alpha_{0}$. Once a best estimate for $\omega$ and $\alpha_{0}$ is found, one can estimate the amount of strain that each analysed fault experienced by finding the strain that minimises $\Delta_{i}$, using equation (12). 
Gomez-Rivas, E., Bons, P.D., Griera, A., Carreras, J., Druguet, E., and Evans, L. (2007). Strain and vorticity analysis using small-scale faults and associated drag folds. Journal of Structural Geology, 29, 1882-1899
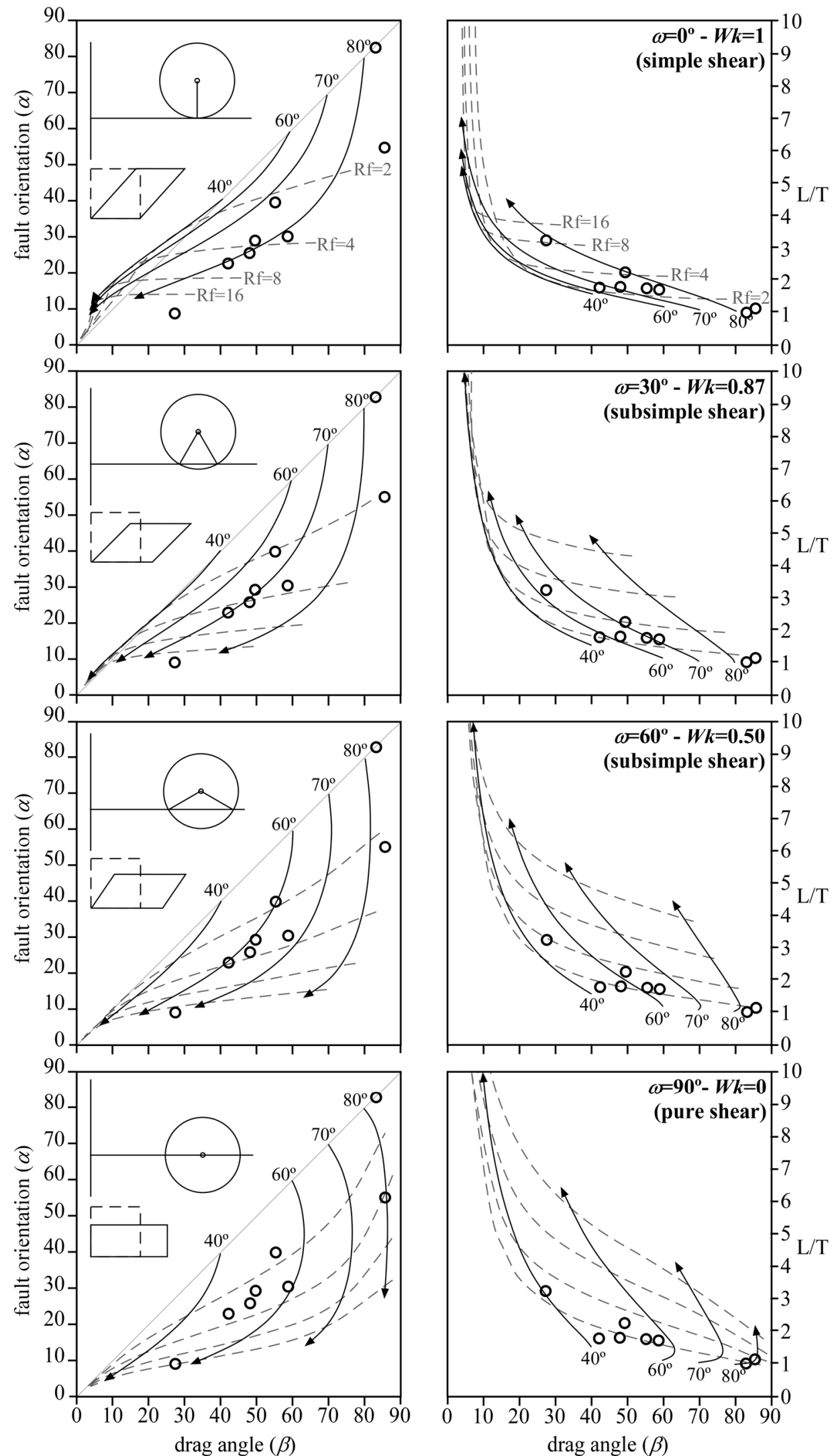

Fig. 5. Curves of $\alpha$ and $L / T$ as a function of $\beta$ for different vorticities and starting orientations of the fault. This chart can be used to estimate $R f$, vorticity and initial fault angle in the field. Insets show the Mohr-circle for stretch for an $R_{f}$-value of 4 . Eight data points from Rabassers de Dalt are plotted in each of the graphs. The pair of curves that best fits these data is the one for $\omega=0^{\circ}$ (simple shear) and $\alpha_{0}$ is between $70^{\circ}$ and $80^{\circ}$. The highest strain the rock experienced is estimated to be between $R_{f}=8$ to 16 (shear strain is 2.5 to 3.8). 


\section{Validation of the method}

\subsection{Introduction}

In order to ascertain the validity of the method, it has been tested on several analogue and numerical experiments with different initial fault angles and different boundary conditions. First, the method has been applied to a simple shear analogue model from Exner et al. (2004) and later to a pure shear experiment of our own. We also ran a series of numerical experiments with a variety of initial angles and vorticities, ranging from pure to simple shear. In all cases, we measured $\alpha, \beta$ and $L / T$ of a single drag fold structure at different stages of its development, and applied the least-squares best-fit routine to the data.

\subsection{Validation on a simple shear analogue experiment}

Exner et al. (2004) studied drag fold structures at a fault in a deforming a homogeneous, linear viscous matrix material (PDMS) in a ring shear rig. Each of their models started with a predefined fault, lubricated using liquid soap and silicone oil. They tracked the offset and deflection of foliation around the fault using a marker grid. We used published images of one experiment for $\alpha_{0}=90^{\circ}$ according to the authors (Fig 6, after their figure 6). It should be noted that the actual starting angle in that experiment was slightly less, about $87^{\circ}$. The fault initially has antithetic slip and develops reverse drag folds. At a shear strain of 2.3 , the fault has rotated $67^{\circ}$ and slip reverses to become synthetic. In the terminology of Grasemann et al. (2003) the system evolves from a reverse-drag a-type, to a normal-drag s-type flanking fold.

Nine groups of data $(\alpha, \beta, L / T)$ were measured from the figures of Exner et al. (2004) up to a shear strain of 1.8 , where the finite offset along the fault is still antithetic. With our analysis (Fig. 7) we obtained an estimated initial fault angle of $85^{\circ}$ (true value $87^{\circ}$ ) and an angle between flow apophyses of $\omega=3^{\circ}$ or $W k=1.00$ (true value $0^{\circ}$ and 1.00 respectively).
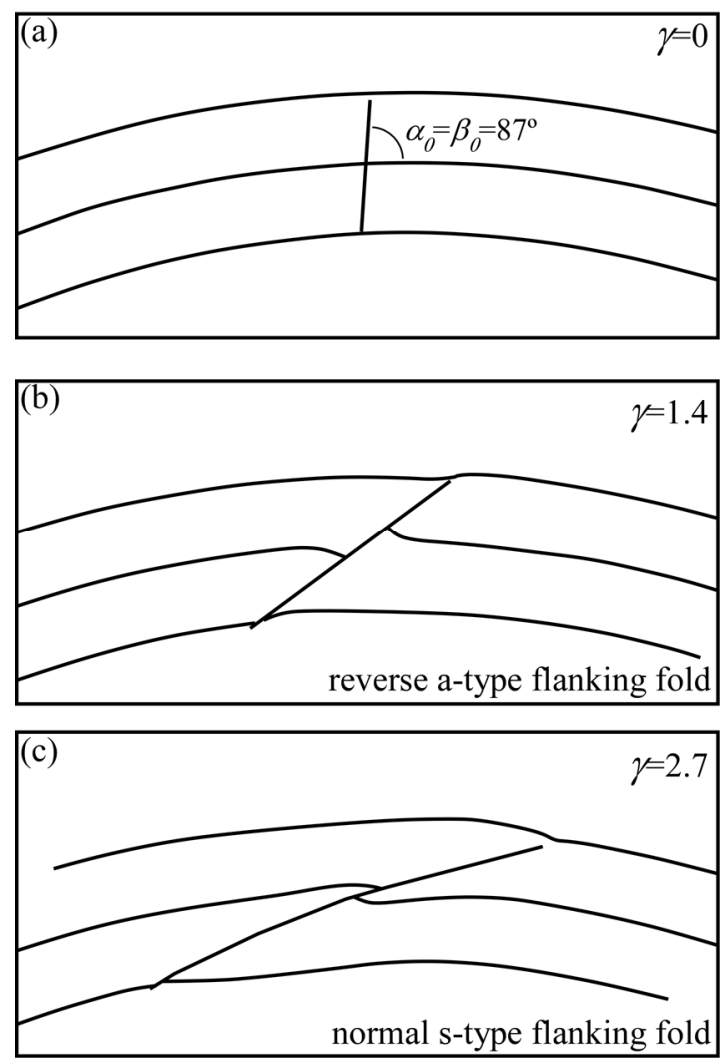

Fig. 6. Progressive development of a reverse a-type flanking fold (Modified from Exner et al. (2004).

\subsection{Validation on pure shear analogue experiments}

To test the method on a pure shear case, we used the deformation apparatus described by Carreras and Ortuño (1990) and Druguet and Carreras (2006). The deforming medium was soft, commercially available plasticine. This material has been characterized as non-linear elasto-viscous with a stress exponent of 3, an effective viscosity $\eta \sim 4 \cdot 10^{7} \mathrm{~Pa} \cdot \mathrm{s}$ at the experimental conditions, a density $\rho$ of $1.15 \cdot 10^{3} \mathrm{~kg} / \mathrm{m}^{3}$, and shear modulus $G \sim 10^{5} \mathrm{~Pa}$ (Gomez-Rivas, 2005). The model had initial dimensions of $29 \times 15 \times 10 \mathrm{~cm}$ and was deformed in pure shear at a temperature of $26^{\circ} \mathrm{C}$ and at a strain rate of $4 \cdot 10^{-5} \mathrm{~s}^{-1}$. Since tests with a lubricated cut, as used by Exner et al. (2004), failed, we simulated the fault with a lenticular fracture that was filled with much softer PDMS (Fig. 8). The fault was initially 
oriented $60^{\circ}$ to the extension direction. A 5 $\mathrm{mm}$ grid was drawn on the surface of the plasticine. Plane-strain pure-shear deformation was applied by moving the sides of the sample, while keeping the sample thickness constant at $10 \mathrm{~cm}$.
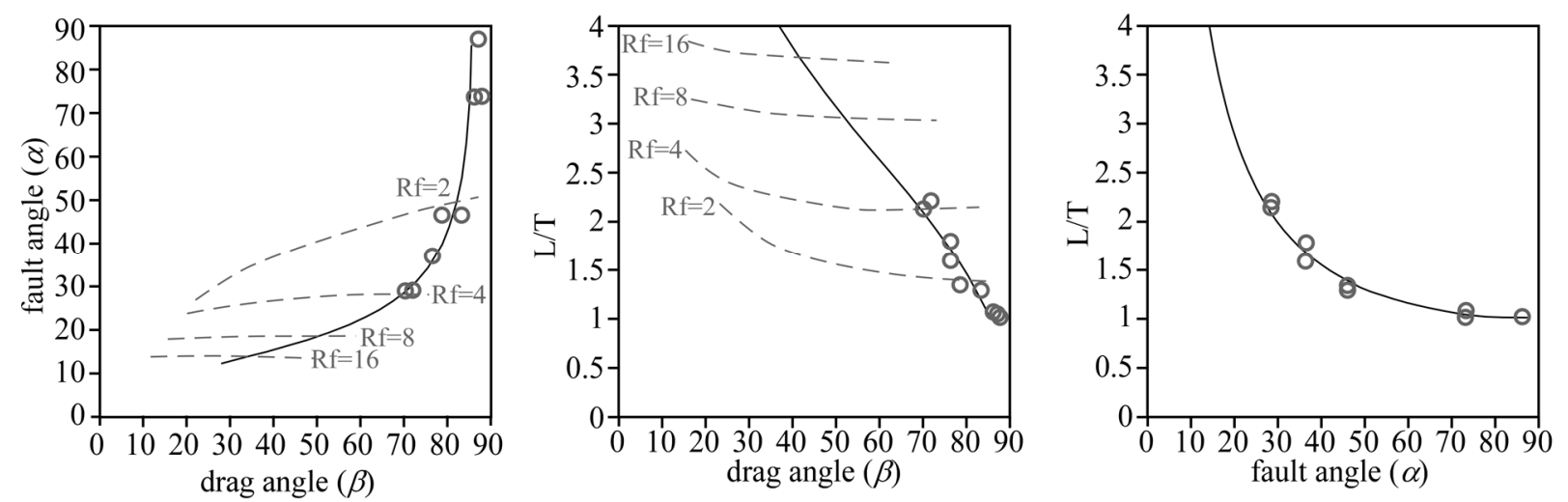

Fig. 7. Curves of $\alpha, \beta$ and $L / T$ for simple shear and a starting orientation of the fault of $85^{\circ}$, which best fit the data measured from the experiment of Exner et al. (2004).

Shortening lead to a rotation of the fault and the development of reverse-drag folds. The soft PDMS was squeezed towards the tips of the fault, where wing cracks developed. Despite these developments, our analysis of six data groups, measured every $10 \%$ shortening, gave a good estimate of the vorticity $\left(89^{\circ}\right.$ instead of $\left.90^{\circ}\right)$ and initial fault angle $\left(59^{\circ}\right.$ instead of $\left.60^{\circ}\right)$ (Fig. 9).
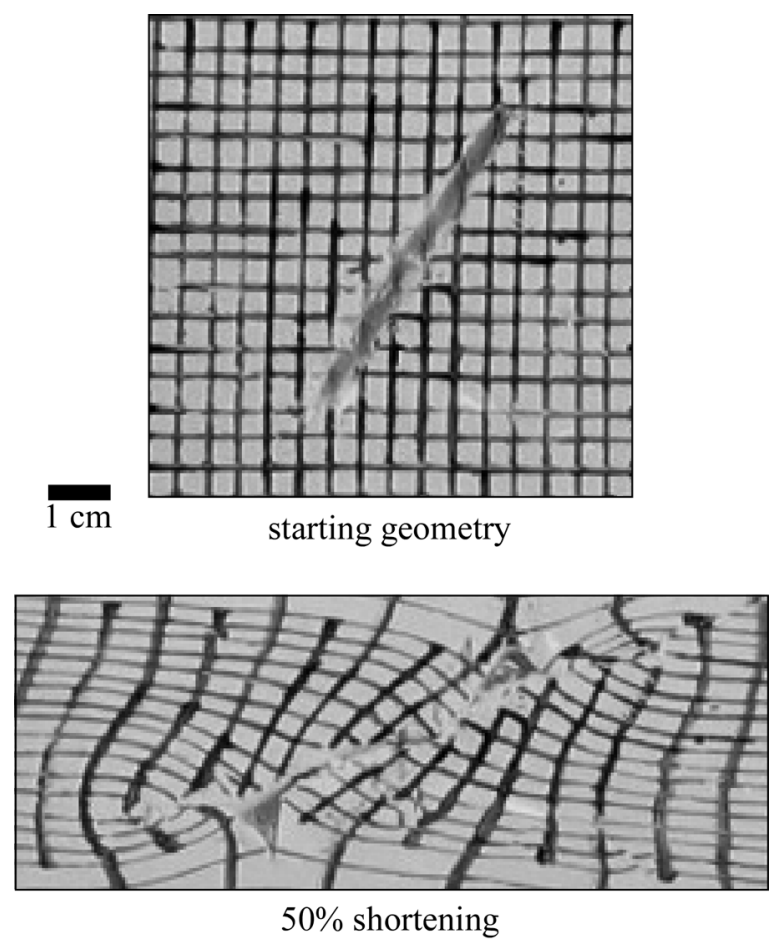

Fig. 8. Initial and final stage of a pure shear analogue model showing the evolution of an pre-existing fault (a PDMS-filled lens) and its associated drag folds. The side of each square is $0,5 \mathrm{~cm}$. wide.

\subsection{Validation on finite element numerical simulations}

As shown above, our proposed method appears to work well for ideal pure and simple shear deformation. Unfortunately, experimental data were not available for general shear. We therefore conducted a series of finite element models to test the method for a range of vorticities and initial fault angles. For the numerical simulations we used the code BASIL (Barr and Houseman, 1996) that is linked to the modelling platform Elle (Jessell et al., 2001).

The models were two-dimensional and consisted of a square containing a narrow ellipse in the centre (Fig. 10). The host rock was simulated with a homogeneous isotropic linear viscous material with a viscosity $(\eta)$ of one. A single layer of viscosity 1.1 represented the foliation in the host rock. Like Grasemann et al. (2003) we simulated the fault in the centre of each model with a narrow ellipse with a viscosity of 0.01 . Two types of initial geometries were considered, with the ellipse oriented at $45^{\circ}$ and $75^{\circ}$ to the foliation, respectively. These two models were deformed under different velocity boundary conditions, from simple to pure shear, varying the angle between flow apophyses $(\omega)$ by $30^{\circ}$ (Table 1 ). The grid was generated with a self-meshing routine using Delauney triangles with a minimum angle of $10^{\circ}$. 
At least 6 groups of data $(\alpha, \beta, L / T)$ were measured at different finite strain from each simulation, and analyzed to determine the vorticity and initial fault angle. The difference between true and estimated values are plotted in Fig. 11, and listed in table 1. Differences in $W k$ ranges from 0 to 0.1 at the most, and estimated initial fault angles are within $7^{\circ}$ of the true values.

Summarizing, in all tests the results from the analysis closely match the known true values of the physical and numerical experiments, allowing us to apply the method to naturally deformed rocks with confidence.
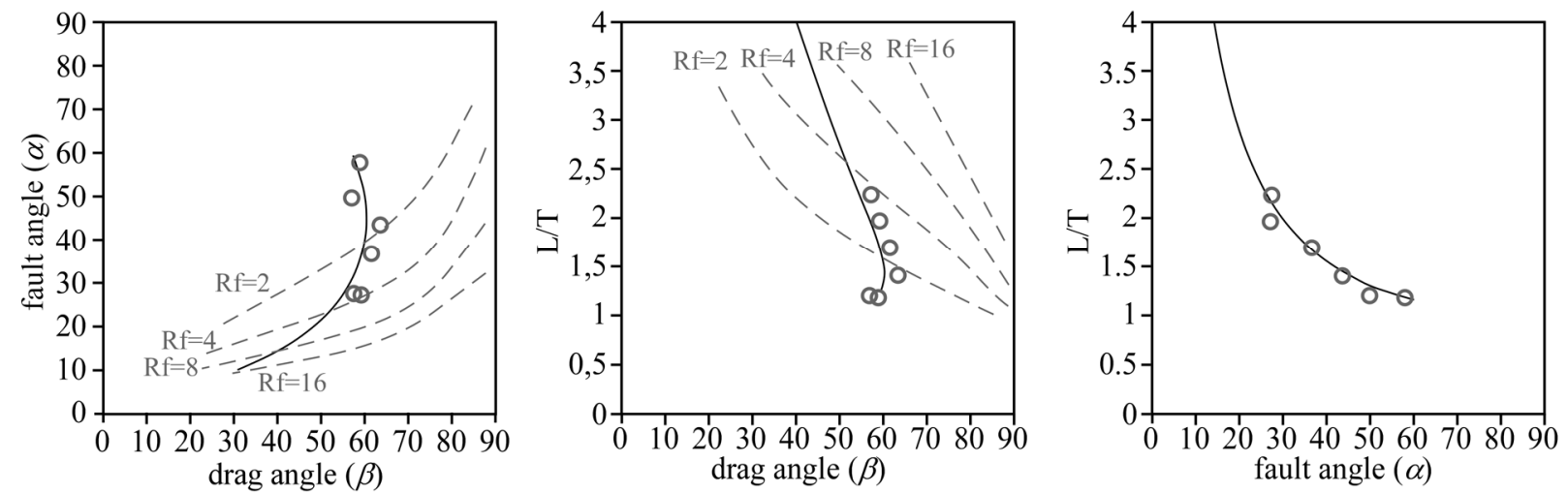

Fig. 9. Curves of $\alpha, \beta$ and $L / T$ for pure shear and a starting orientation of the fault of $59^{\circ}$. The measured data points of our experiment fit precisely to the calculated curves.
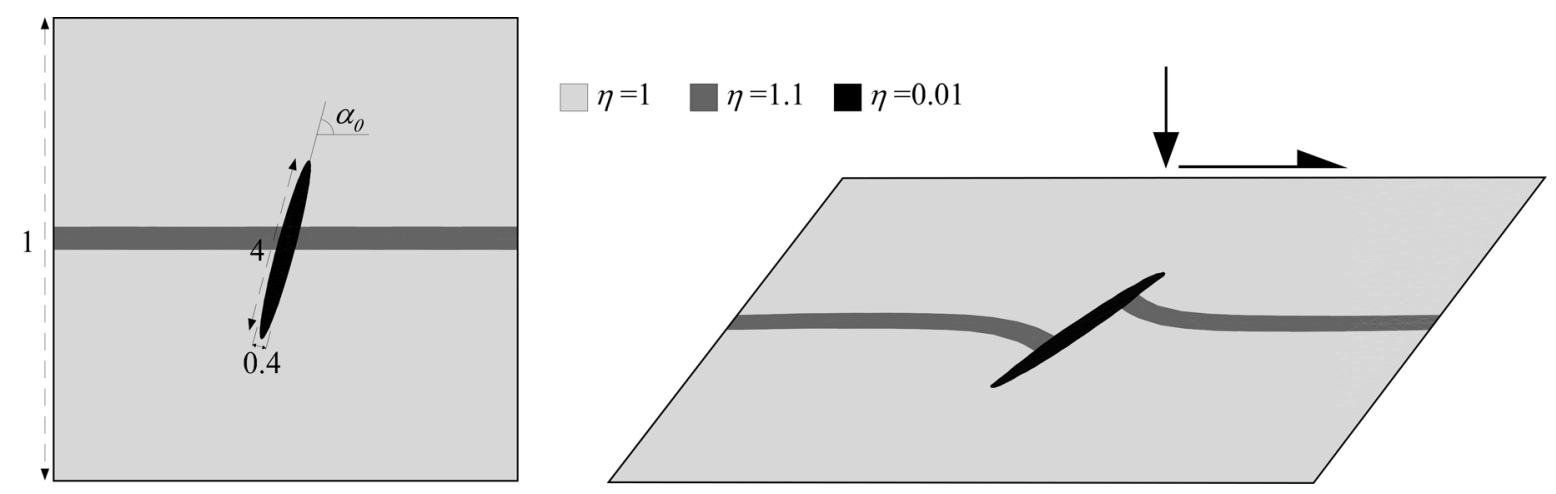

Fig. 10. (a) Initial configuration in finite element simulations with BASIL for an initial fault angle of $75^{\circ}$. (b) Geometry at the end of a simulation for $W k=0.5$ at a finite strain of $R f=2.6$.

\section{Strain analysis applied to the Mas Rabassers de Dalt outcrop}

A total of 29 small antithetic faults in the quartzite layer at Mas Rabassers de Dalt (Fig. 3) were analyzed to estimate the deformation experienced by this rock. The finite fault orientations ranged from $\alpha=10$ to $64^{\circ}$ (Table $2)$. The data were processed with the software described in section 3.3. The results showed an initial fault angle $\left(\alpha_{0}\right)$ of $78^{\circ}$ and an angle between flow apophyses $(\omega)$ of $3^{\circ}$, which gives a bulk kinematic vorticity number $(W k)$ of 1.00 (dextral simple shear). The highest strain was recorded by fault structure number 5 (at locality $\mathrm{C}$ in Fig. 3) with a finite strain of about $R f=8$ to 16 , which is equivalent to a shear strain of about 2.5 to 3.8 .

The dextral simple shear inferred from this analysis is consistent with the field observations: the quartzite layer is oriented parallel to the zone of highest D3 shear strain. Only one small fault (locality F) was found away from the main shear zone, but this one, with a high angle of $\alpha=54^{\circ}$ to the foliation, experienced less finite shear strain. 


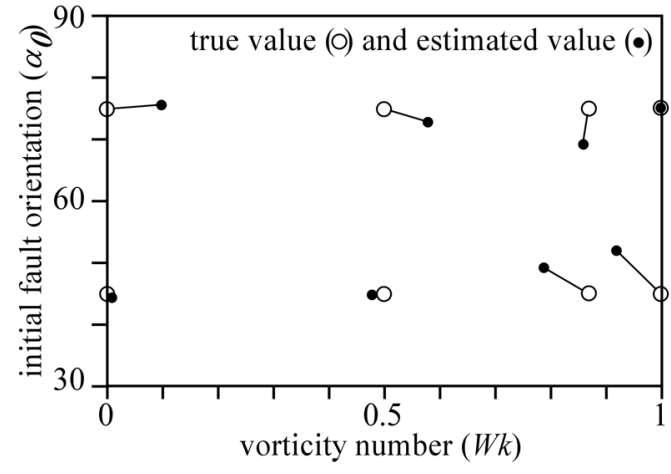

Fig. 11. Comparison of true (open dots) and estimated (closed dots) values of kinematic vorticity number and initial fault angles, for eight numerical simulations with BASIL.

Table 1

True and calculated values of bulk kinematic vorticity number $(W k)$ and initial fault angle $\left(\alpha_{0}\right)$ for eight finite element simulations, showing that errors in $W k$ are below 0.1 and in $\alpha_{0}$ below $7^{\circ}$

\begin{tabular}{|c|c|c|c|c|c|c|}
\hline $\begin{array}{l}\text { Initial } \omega \\
\text { angle }\end{array}$ & $\begin{array}{l}\text { Initial } \\
W k\end{array}$ & $\begin{array}{l}\text { Calculated } \\
W k\end{array}$ & $\begin{array}{l}W k \\
\text { error }\end{array}$ & $\begin{array}{l}\text { Initial } \\
\alpha_{0}\end{array}$ & $\begin{array}{l}\text { Calculated } \\
\alpha_{0}\end{array}$ & $\begin{array}{l}\alpha_{0} \\
\text { error }\end{array}$ \\
\hline$\overline{0^{\circ}}$ & 1.00 & 0.92 & 0.08 & $45^{\circ}$ & $52.0^{\circ}$ & $7.0^{\circ}$ \\
\hline $0^{\circ}$ & 1.00 & 1.00 & 0.00 & $75^{\circ}$ & $75.1^{\circ}$ & $0.1^{\circ}$ \\
\hline $30^{\circ}$ & 0.87 & 0.79 & 0.08 & $45^{\circ}$ & $48.8^{\circ}$ & $3.8^{\circ}$ \\
\hline $30^{\circ}$ & 0.87 & 0.86 & 0.01 & $75^{\circ}$ & $69.0^{\circ}$ & $6.0^{\circ}$ \\
\hline $60^{\circ}$ & 0.50 & 0.48 & 0.02 & $45^{\circ}$ & $44.7^{\circ}$ & $0.3^{\circ}$ \\
\hline $60^{\circ}$ & 0.50 & 0.58 & 0.08 & $75^{\circ}$ & $72.7^{\circ}$ & $2.3^{\circ}$ \\
\hline $90^{\circ}$ & 0.00 & 0.01 & 0.01 & $45^{\circ}$ & $44.1^{\circ}$ & $0.9^{\circ}$ \\
\hline $90^{\circ}$ & 0.00 & 0.10 & 0.10 & $75^{\circ}$ & $75.7^{\circ}$ & $0.7^{\circ}$ \\
\hline
\end{tabular}

The available data set it is large enough to test the precision of the method. This was done by randomly selecting subsets of $5,9,13$,
17, 21 and 25 data and using these subsets to determine vorticity and initial fault angle. Ten different random subsets were processed for each size of the subset. Figure 13 shows that even very small datasets ( 5 to 9 data) already give approximately the right solution. It should also be noted that least-squares best fit using 29 data points (measured by EGR) produced almost identical results to that using the graphs (Fig. 5) on only eight data points independently collected by someone else (PDB). This not only indicates that the graphical method with a limited data set produces good results but also that user bias does not seem to be a significant factor in the analysis.

\section{Discussion and conclusions}

In this paper we have shown that small-scale faults with drag folds can be used to determine vorticity, initial fault angle, and estimate of the minimum finite strain since first fault nucleation. This is a useful addition to the structural geologist's "toolbox" because relatively few methods exist to determine and quantify vorticity (Ghosh, 1987; Passchier and Urai, 1988; Wallis, 1992; Short and Johnson, 2006).
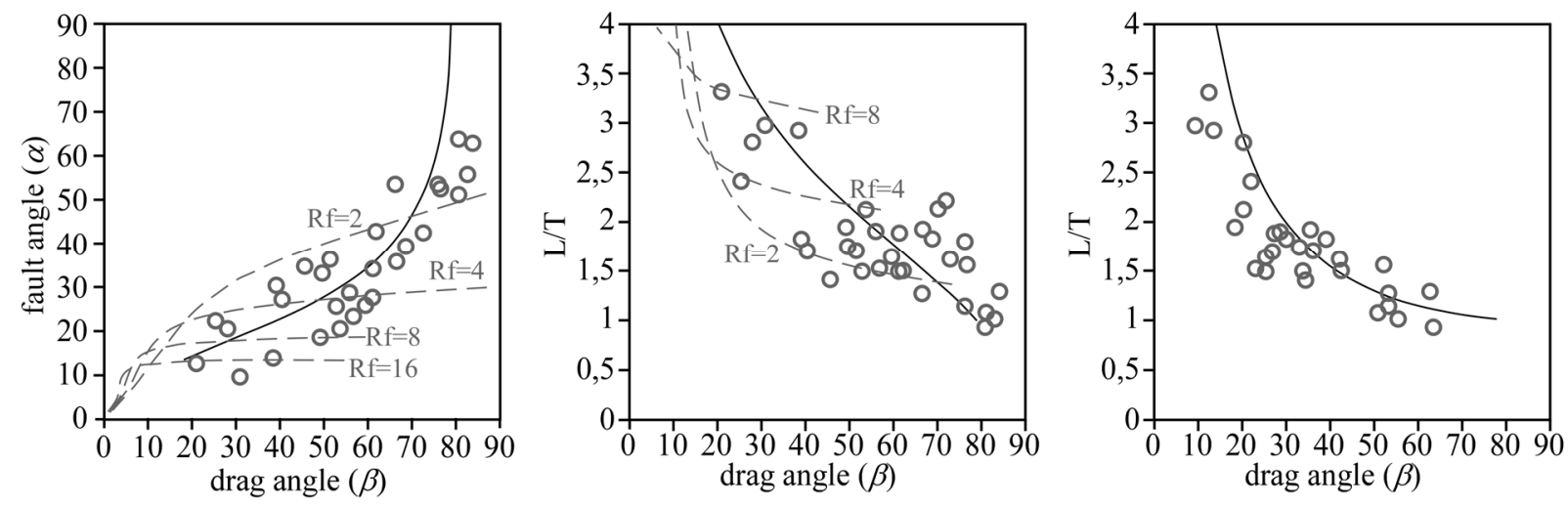

Fig. 12. Curves of $\alpha, \beta$ and $L / T$ for an angle between flow apophyses of $3^{\circ}$ and an initial fault angle of $78^{\circ}$. The plotted data correspond to the measured parameters at Mas Rabassers de Dalt.

The initial fault angle $\left(\alpha_{0}\right)$ can usually be estimated in the field, by finding the steepest fault with the least offset and drag fold bending. If this $\alpha_{0}$ is determined independently first, it can of course be used in the subsequent determination of the angle between flow apophyses $(\omega)$, either when using the graphs (Fig. 5 and Appendix), or 
when using the least-squares technique. In the latter case one can set $\alpha_{0}$ and only iterate over $\omega$ and $R f$ to find the best fit. However, without using a priori knowledge of $\alpha_{0}$, the method appears robust and produced estimated values close $\left(<10^{\circ}\right)$ to the true ones in all tests on experiments and numerical simulations.

Table 2

Values of $\alpha, \beta$ and $L / T$ measured from the Rabassers de Dalt outcrop

\begin{tabular}{lllll}
\hline locality & data group & $\alpha_{0}$ & $\beta_{0}$ & L/T \\
\hline A & 1 & 14 & 39 & 2.93 \\
B & 2 & 36 & 67 & 1.93 \\
C & 3 & 53 & 77 & 1.56 \\
& 4 & 21 & 28 & 2.81 \\
& 5 & 10 & 31 & 2.98 \\
& 6 & 28 & 61 & 1.89 \\
D & 7 & 13 & 21 & 3.31 \\
& 8 & 30 & 39 & 1.83 \\
& 9 & 26 & 53 & 1.50 \\
& 10 & 35 & 46 & 1.42 \\
& 11 & 33 & 50 & 1.75 \\
& 12 & 63 & 84 & 1.30 \\
& 13 & 26 & 60 & 1.65 \\
& 14 & 29 & 56 & 1.91 \\
& 15 & 19 & 49 & 1.95 \\
& 16 & 42 & 73 & 1.62 \\
& 17 & 54 & 66 & 1.28 \\
& 18 & 39 & 69 & 1.83 \\
& 19 & 64 & 81 & 0.94 \\
& 20 & 34 & 61 & 1.50 \\
& 21 & 36 & 52 & 1.71 \\
& 22 & 43 & 62 & 1.50 \\
E & 23 & 21 & 54 & 2.13 \\
& 24 & 27 & 41 & 1.71 \\
& 25 & 23 & 57 & 1.53 \\
& 26 & 22 & 26 & 2.42 \\
& 27 & 56 & 83 & 1.02 \\
& 28 & 51 & 81 & 1.08 \\
& 29 & 54 & 76 & 1.15 \\
\hline
\end{tabular}

In the field study with 29 measured faults, simple shear deformation was obtained, which is consistent with the known local deformation at Mas Rabassers de Dalt. Still, one cannot determine the exact vorticity that the quartzite experienced with only orientations of foliations, fold axes, and other structural elements. Local field observations made so far only indicated a dominant simple shear component, leaving open sub-simple shear with some shortening or stretching parallel to the shear plane. With the new analysis of the faults with drag folds the kinematic vorticity number is better constrained.

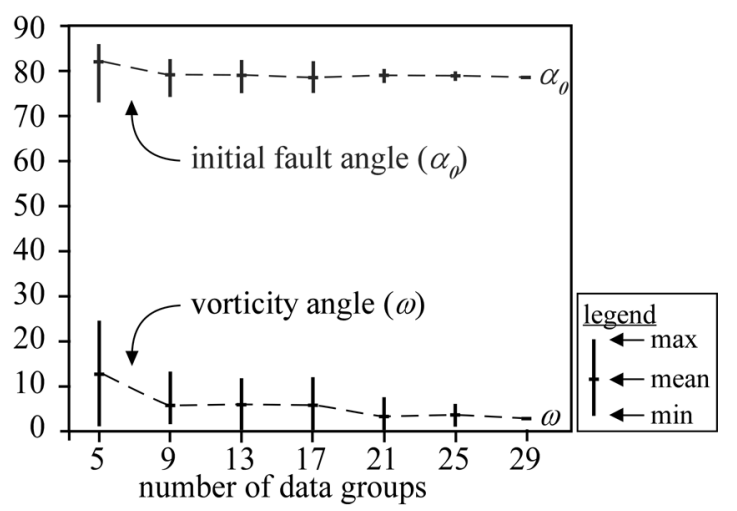

Fig. 13. Graph showing the stability of this analytical method using a different number of groups of measurements. The solution becomes stable using less than 10 groups of data.

In conclusion, we propose a new method to determine vorticity, initial fault angle and finite strain using small-scale faults with drag folds. Theory and validation tests on experiments and numerical simulations show that the method is robust, provided the following assumptions hold: (a) the structures nucleate at different stages during deformation, and therefore record different amounts of strain, (b) the faults all nucleate in approximately the same orientation $\left(\alpha_{0}\right)$, (c) the flow kinematics do not change during deformation, (d) the structures are isolated to avoid interference between adjacent structures, and (e) the faults are discrete, so that the drag angle $(\beta)$ can be determined accurately. The last assumption means that ductile shear bands (Fig. 1b) are not suitable for this method.

Although a least-squares best fit routine is preferred to obtain the best estimate of kinematic vorticity number, initial fault angle and minimum finite strain, charts can be used to obtain a first estimate. 

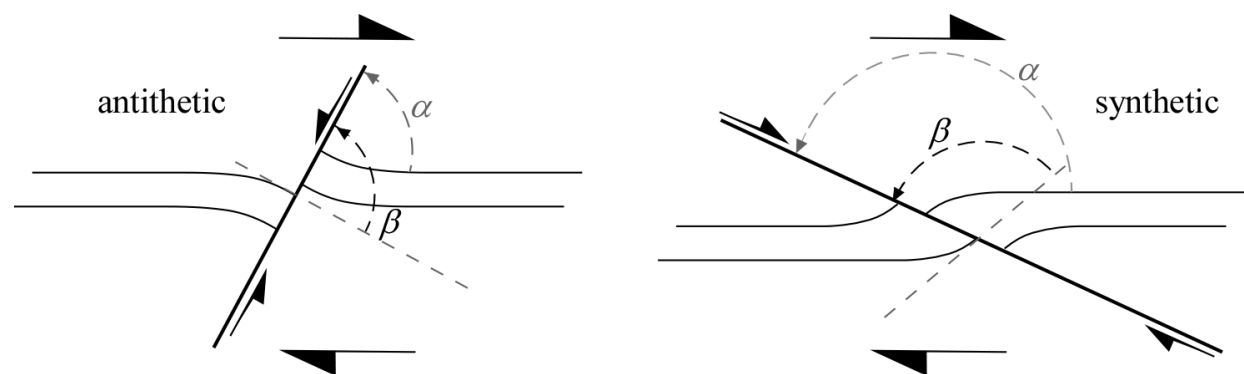

Fig. A1. Definition of parameters
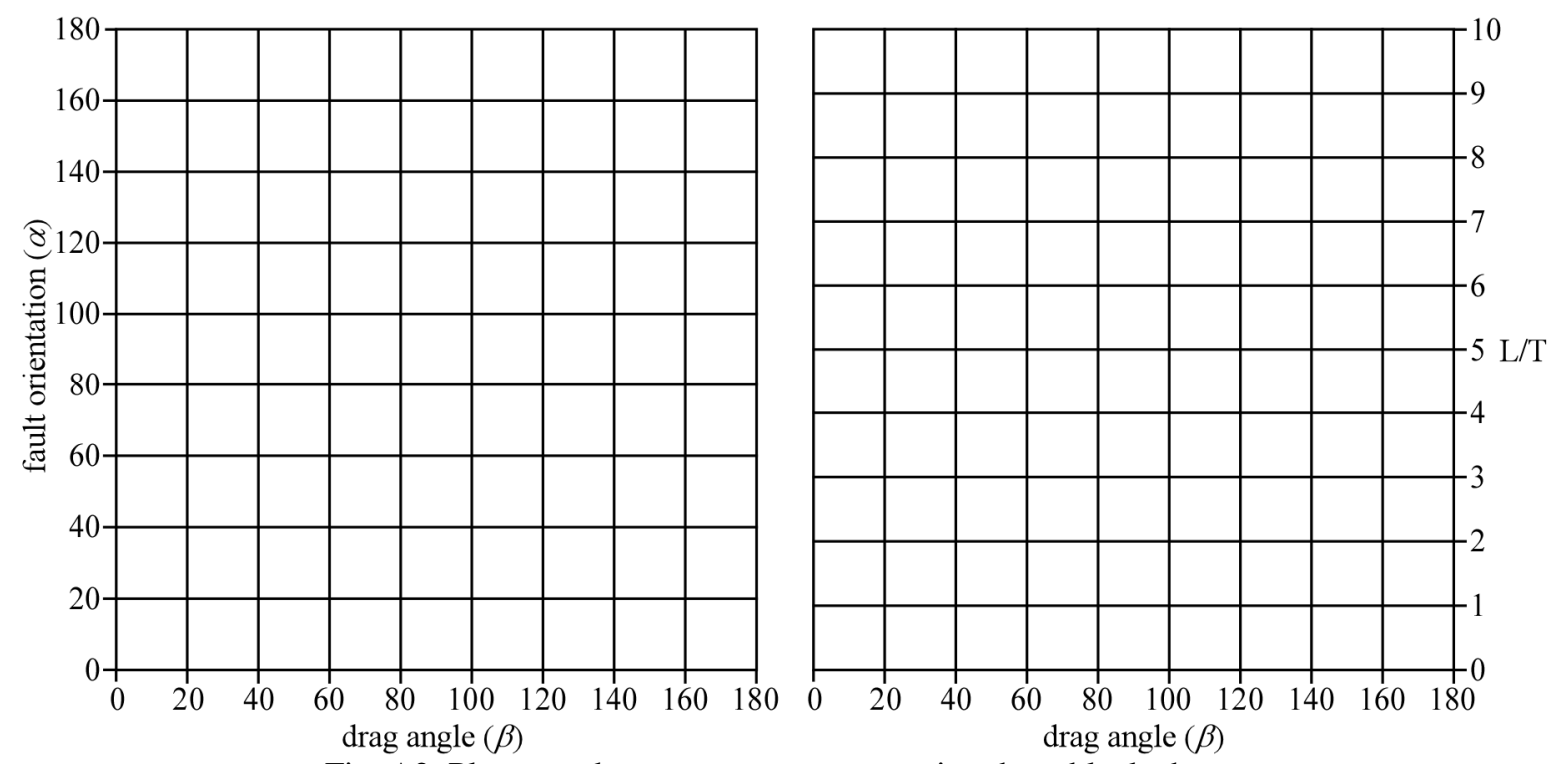

Fig. A2. Plot your data on a transparency using these blank charts

\section{Acknowledgements}

This work was financed through the $\mathrm{PhD}$ grant BES2003-0755 to EGR and research project CGL200403657, both funded by the Spanish Ministry of Education and Science. We thank Jens Becker and Anne Peschler for their help with the BASIL modelling. We gratefully acknowledge D. Jiang and T. Bell, whose constructive reviews greatly improved the manuscript.

\section{Appendix A. Charts to estimate initial fault angle $\left(\alpha_{0}\right)$, vorticity $(\omega)$ and minimum finite strain $(R f)$}

To use these charts, measure the following parameters from a number of fault systems, preferably at different stages of development (Fig. A1):

- The angle between the fault and the foliation away from the fault $(\alpha)$;

- The angle between the fault and the deflected foliation at the fault $(\beta)$;
- The ratio $(L / T)$ of the thickness of a layer away from the fault $(T)$ and the thickness of the same layer parallel to the fault and at the fault $(L)$.

Each pair of graphs is for a certain vorticity, defined by the angle between the flow apophyses $(\omega)$ or the kinematic vorticity number $(W k)$. Arrows in the graphs show $\alpha-\beta$ (left) and $L / T-\beta$ (right) paths as a function of increasing finite strain and initial fault orientation $\left(\alpha_{0}\right)$. Dashed lines are finite strain contours at $R f=2,4,8$, and 16 .

Plot your measurements on a transparency, using the blank pair of graphs provided (Fig. A2). Then overlay your plot on the graphs (Figs. A3 to A6) and find the vorticity where your data most closely follow one single arrow on both graphs. The arrow fitting your data points provides you with the starting orientation of the faults. Ideally, each data point should have the same finite strain in both graphs as well. 
Gomez-Rivas, E., Bons, P.D., Griera, A., Carreras, J., Druguet, E., and Evans, L. (2007). Strain and vorticity analysis using small-scale faults and associated drag folds. Journal of Structural Geology, 29, 1882-1899
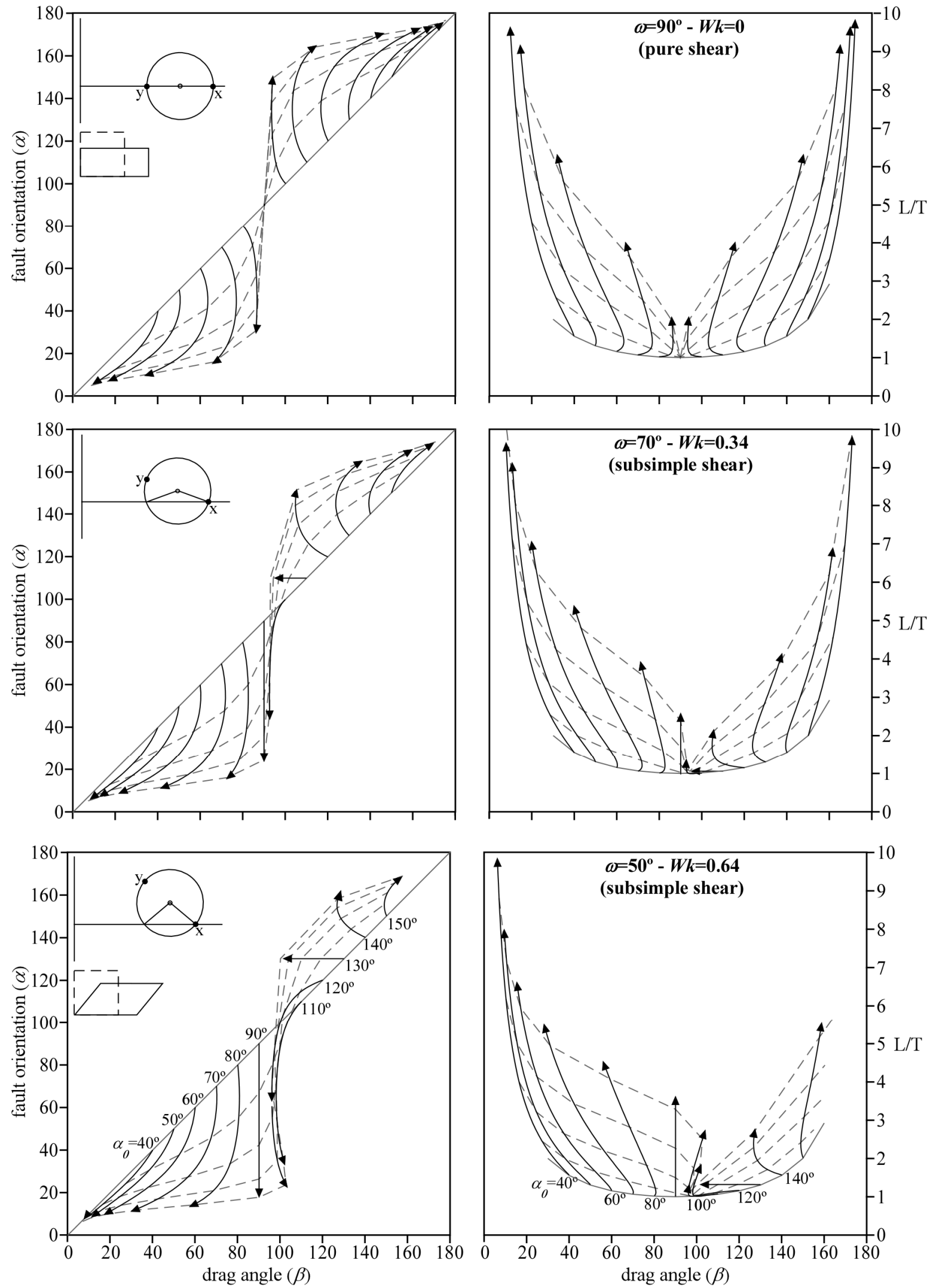
Gomez-Rivas, E., Bons, P.D., Griera, A., Carreras, J., Druguet, E., and Evans, L. (2007). Strain and vorticity analysis using small-scale faults and associated drag folds. Journal of Structural Geology, 29, 1882-1899
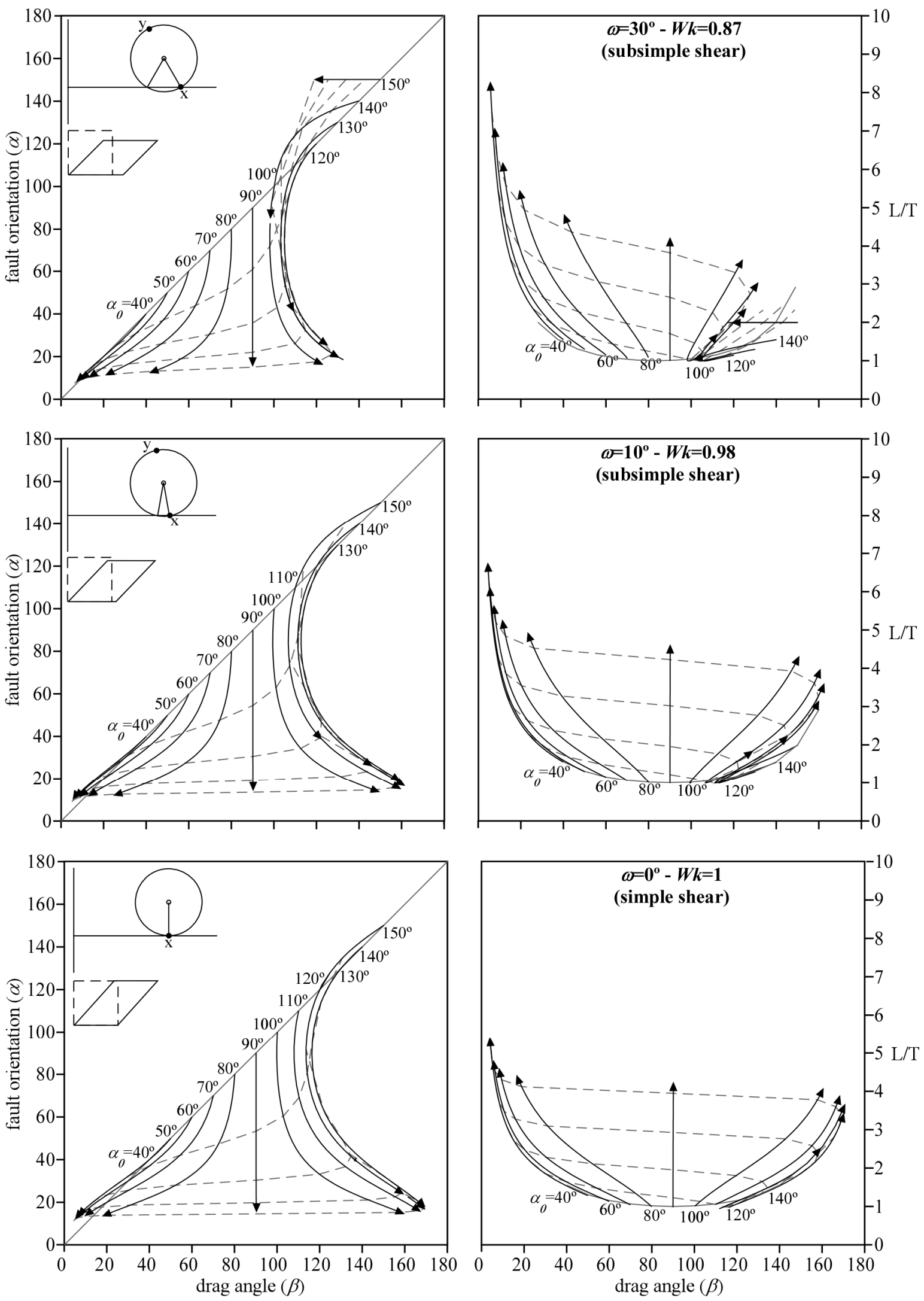
Gomez-Rivas, E., Bons, P.D., Griera, A., Carreras, J., Druguet, E., and Evans, L. (2007). Strain and vorticity analysis using small-scale faults and associated drag folds. Journal of Structural Geology, 29, 1882-1899
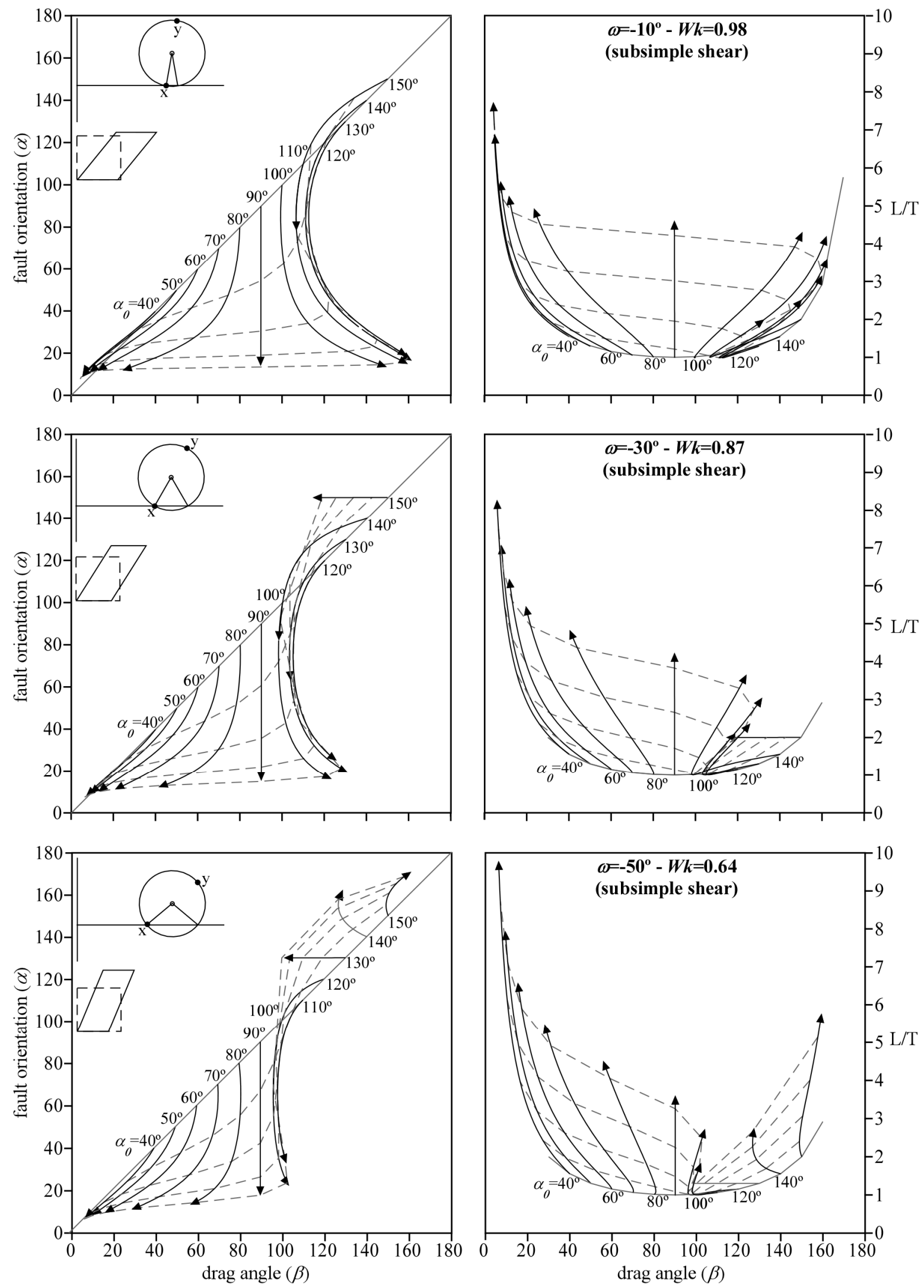
Gomez-Rivas, E., Bons, P.D., Griera, A., Carreras, J., Druguet, E., and Evans, L. (2007). Strain and vorticity analysis using small-scale faults and associated drag folds. Journal of Structural Geology, 29, 1882-1899
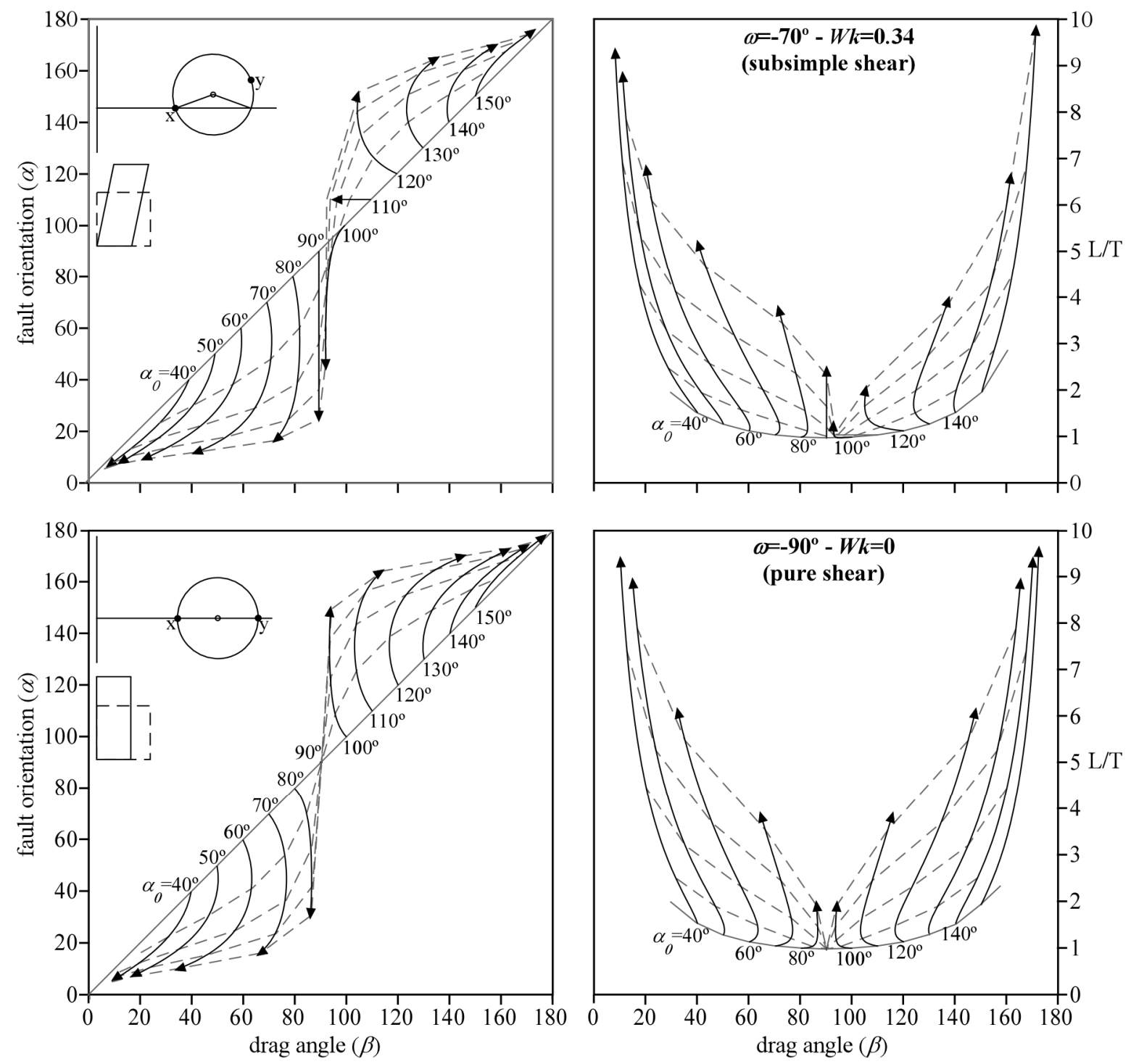

Fig. A3 to A6. Curves of $\alpha$ and $L / T$ as a function of $\beta$ for different vorticities and starting orientations of the fault $\left(\alpha_{0}\right)$. Insets show the Mohr-circle for stretch for an $R_{f}$-value of 4 . Dashed lines are finite strain contours at $R f=2,4$, 8 , and 16.

\section{References}

Barnolas, A.,Chiron, J. C. 1996. Synthèse géologique et géophysique des Pyrénées. BRGM-ITGE. 729 pp.

Barr, T. D. and Houseman, G. 1996. Deformation fields around a fault embedded in a non-linear ductile medium. Geophysical Journal International 125, 473-490.

Bons, P. D., Druguet, E., Hamann, I., Carreras, J., Passchier, C. W. 2004. Apparent boudinage in dykes. Journal of Structural Geology 26, 625-636.

Carreras, J. 2001. Zooming on Northern Cap de Creus shear zones. Journal of Structural Geology 23, 14571486.

Carreras, J., Casas, J. M. 1987. On folding and shear zone-development: a mesoscale structural study on the transition between two different tectonic styles. Tectonophysics 135, 87-98.
Carreras, J., Druguet, E., Griera, A. 2005. Shear zonerelated folds. Journal of Structural Geology 27, 1229-1251.

Carreras, J., Ortuño, F. 1990. Fundamento geométrico y cinemática de la modelización teórica y experimental de deformaciones no-coaxiales. Acta Geológica Hispánica 17, 219-225.

Coelho, S., Passchier , C. W., Grasemann, B. 2005. Geometric description of flanking structures. Journal of Structural Geology 27, 597-606.

Druguet, E. 1997. The structure of the NE Cap de Creus Peninsula. Unpublished $\mathrm{PhD}$ thesis. Universitat Autònoma de Barcelona.

Druguet, E. 2001. Development of high thermal gradients by coeval transpression and magmatism during the variscan orogeny: Insights from the cap de creus (Eastern Pyrenees). Tectonophysics 332, 275-293. 

using small-scale faults and associated drag folds. Journal of Structural Geology, 29, 1882-1899

Druguet, E., Carreras, J. 2006. Analogue modelling of syntectonic leucosomes in migmatitic schists. Journal of Structural Geology 28, 1734-1747.

Druguet, E., Hutton, D. H. W. 1998. Syntectonic anatexis and magmatism in a mid-crustal transpressional shear zone: an example from the Hercynian rocks of the eastern Pyrenees. Journal of Structural Geology 20, 905-916.

Druguet, E., Passchier, C. W., Carreras, J., Victor, P., Den Brok, S. 1997. Analysis of a complex highstrain zone at Cap de Creus, Spain. Tectonophysics 280, 31-45.

Ebner, M., Grasemann, B. 2006. Divergent and convergent non-isochoric deformation. Journal of Structural Geology 28, 1725-1733.

Exner, U., Mancktelow, N. S., Grasemann, B. 2004. Progressive development of s-type flanking folds in simple shear. Journal of Structural Geology 26, 2191-2201.

Fusseis, F., Handy, M. R., Schrank, C. 2006. Networking of shear zones at the brittle-to-viscous transition (Cap de Creus, NE Spain). Journal of Structural Geology 28, 1228-1243.

Gayer, R. A., Powell, D. B., Stephen, R. 1978. Deformation against metadolerite dykes in the Caledonides of Finnmark, Norway. Tectonophysics 46, 99-115.

Gomez-Rivas, E. 2005. Shear bands en materiales anisótropos: modelización analógica en condiciones de deformación coaxial. Unpublished MSc thesis. Universitat Autònoma de Barcelona.

Ghosh, S. K. 1987. Measure of non-coaxiality. Journal of Structural Geology 9, 111-114.

Grasemann, B., Martel, S., Passchier, C. 2005. Reverse and normal drag along a fault. Journal of Structural Geology 27(6), 999-1010.

Grasemann, B., Stüwe, K. 2001. The development of flanking folds during simple shear and their use as kinematic indicators. Journal of Structural Geology 23(4), 715-724.

Grasemann, B., Stüwe, K., Vannay, J.-C. 2003. Sense and non-sense of shear in flanking structures. Journal of Structural Geology 25, 19-34.

Harris, L. B. 2003. Folding in high-grade rocks due to back-rotation between ductile shear zones. Journal of Structural Geology 25, 223-240.

Harris, L. B., Koyi, H. A., Fossen, H. 2002. Mechanisms for folding of high-grade rocks in extensional tectonic settings. Earth Science Reviews 59, 163-210.
Hudleston, P. J. 1989. The association of folds and veins in shear zones. Journal of Structural Geology 11, 949-957.

Jessell, M., Bons, P. D., Evans, L., Barr, T., Stüwe, K. 2001. Elle: the numerical simulation of metamorphic and deformation microstructures. Computers and Geosciences 27, 17-30.

Kocher, T., Mancktelow, N. S. 2005. Dynamic reverse modelling of flanking structures: a source of quantitative kinematic information. Journal of Structural Geology 27, 1346-1354.

Kocher, T., Mancktelow, N. S. 2006. Flanking structure development in anisotropic viscous rock. Journal of Structural Geology 28, 1139-1145.

Koyi, H. A., Skelton, A. 2001. Centrifuge modelling of the evolution of low-angle detachment faults from high-angle normal faults. Journal of Structural Geology 23, 1179-1185.

Means, W.D., Hobbs, B.E., Lister, G.S., Williams, P.F. 1980. Vorticity and non-coaxiality in progressive deformations. Journal of Structural Geology 2, 371378.

Odonne, F. 1990. The control of deformation intensity around a fault: natural and experimental examples. Journal of Structural Geology 12, 911-921.

Passchier, C. W. 1998. Monoclinic model shear zones. Journal of Structural Geology 20, 1121-1137.

Passchier, C. W. 2001. Flanking structures. Journal of Structural Geology 23, 951-962.

Passchier, C. W., Urai , J. L. 1988. Vorticity and strain analysis using Mohr diagrams. Journal of Structural Geology 10, 755-763.

Ramsay, J. F., Huber, M. I. 1983. The techniques of modern structural geology. Academic Press, London.

Schmid, D. W., Podladchikov, Y. Y. 2003. Analytical solutions for deformable elliptical inclusions in general shear. Geophysical Journal International 155, 269-288.

Short, H. A., Johnson, S. E. 2006. Estimation of vorticity from fibrous calcite veins, central Maine, USA. Journal of Structural Geology 28, 1167-1182.

Wallis, S. R. 1992. Vorticity analysis in a metachert from the Sanbagawa belt, SW Japan. Journal of Structural Geology 14, 271-280.

Wiesmayr, G.,Grasemann, B. 2005. Sense and nonsense of shear in flanking structures with layerparallel shortening: implications for fault-related folds. Journal of Structural Geology 27, 249-264. 